\title{
N Um estudo sobre as anáforas em hipertextos
}

\author{
Wellington Gomes de Souza \\ Universidade do Estado do Rio Grande do Norte \\ https://orcid.org/0000-0002-9751-9030 \\ Lidiane de Morais Diógenes Bezerra \\ Universidade do Estado do Rio Grande do Norte \\ http://orcid.org/0000-0002-9569-5567
}

\begin{abstract}
RESUMO
A literatura sobre os estudos dos processos anafóricos explora, comumente, a retomada de referentes em uma dada materialidade textual. Para além disso, a discussão proposta neste artigo parte da ideia de que os objetos de discurso de um texto podem ser transpostos para outras materialidades linguísticas. Nas construções que caracterizam o hipertexto, por exemplo, apresenta-se uma dinamicidade de referentes que permite essa observação. Por isso, o objetivo desta abordagem é discutir sobre os processos referenciais anafóricos em textos veiculados em situações de hipertexto, cuja característica é a possibilidade de trânsito por diversas superfícies linguísticas. Para fundamentar esta análise, tem-se aporte nos estudos de Mondada e Dubois (2003) e Apothéloz (2003) para tratar da referenciação; Alves Filho et al (2017), Xavier (2010), entre outros autores, a fim de discorrer sobre o hipertexto. Para cumprir com o propósito em questão, foram analisadas notícias em que se percebeu o trânsito de referentes de uma superfície textual para outra. Nessa perspectiva, compreende-se que há espaço para a caracterização do que pode ser chamado de anáfora hipertextual, pois, da análise realizada, constatou-se a criação de uma rede anafórica entre os textos. Com isso, conclui-se que esse estudo pode ampliar o campo de visão dos processos referenciais anafóricos, com base na dinamicidade das anáforas para a construção textual de sentidos.
\end{abstract}

PALAVRAS-CHAVE: Referenciação; Anáfora; Hipertexto

\section{A Study on Anaphors in Hypertexts}

\section{ABSTRACT}

The literature on the study of anaphoric processes commonly explores the resumption of referents in a given textual materiality. However, the discussion proposed in this article starts from the idea that the speech objects of a text can be transposed to other linguistic materialities. In the constructions that characterize hypertext, for example, a dynamics of referents allows this observation. Therefore, the objective of this approach is to discuss anaphoric referential processes in texts propagated in hypertext situations, whose characteristic is the possibility of transit through different linguistic surfaces. We support this analysis on the studies by Mondada and Dubois (2003) and Apothéloz (2003) to address referencing; Alves Filho et al (2017), Xavier (2010), among other authors, who discuss hypertext. To account for the purpose in question, we analyzed news in which the transit of referents between textual surfaces is noticed. In this perspective, we understand that there is space for the characterization of what we will call hypertextual anaphor, because, from the analysis performed, we can see the creation of an anaphoric network between the texts. Thus, we conclude that this study can expand the scope of anaphoric referential processes, based on the dynamics of anaphors for the textual construction of meanings.

KEYWORDS: Referencing; Anaphor; Hypertext 


\section{Introdução}

O estudo dos processos referenciais anafóricos é realizado, comumente, a partir da análise das peculiaridades inerentes a determinada superfície textual para o desenvolvimento de um referente e consequente produção de sentidos, defesa de um ponto de vista, entre outros direcionamentos relativos ao processo interativo que se constrói mediante a produção e a recepção de textos.

Nesse contexto, consideramos que a dinamicidade concernente à referenciação não se prende apenas a uma materialidade linguística, sobretudo no que diz respeito ao hipertexto, pois há uma cadeia textual na qual, a nosso ver, os referentes transitam e são reconstruídos do mesmo modo dinâmico que ocorre em um texto impresso.

Com esse pensamento, nosso objetivo é discutir sobre os processos referenciais anafóricos em textos veiculados em situações de hipertexto, cuja característica é a possibilidade de trânsito por diversas superfícies linguísticas. Nessa perspectiva de abordagem, teríamos uma ampliação acerca do caráter intratextual peculiar às anáforas e uma maior dinamicidade em relação às construções e reconstruções da referência.

Os encaminhamentos teóricos desta discussão partem de Mondada e Dubois (2003), Apothéloz (2003), Cavalcante et al (2014), para discorrermos sobre a referenciação, além de Xavier (2010), Braga (2010), entre outros autores que apresentam questões sobre o hipertexto.

Com base na discussão teórica, desenvolvemos uma breve análise de notícias veiculadas em meios digitais, a fim de observar a disposição dos objetos de discurso e seus desdobramentos no interior de cadeias textuais que compõem o hipertexto. Nossa hipótese é que haja campo para discussão acerca de anáforas que podem ser denominadas hipertextuais, porque se inserem em situações que as caracterizam dessa maneira, como é o caso da criação de uma rede anafórica inerente ao hipertexto.

Logo, entendemos que esse viés de análise pode ampliar o campo de estudo dos processos referenciais anafóricos, bem como da referenciação como uma estratégia textual-discursiva que também é hipertextual.

\section{A referenciação e a construção de sentidos}

Os estudos concernentes à construção das ideias sobre referenciação representam uma mudança de perspectiva no tocante à análise das relações entre texto e mundo exterior, pois elas não ocorrem invariavelmente nem de modo estável. A partir dessa estratégia textual-discursiva, concebe-se a ideia de objetos de discurso - ou referentes, que dinamizam as relações discursivas e estão além da percepção simplificada de objetos de mundo, como se defendia em uma perspectiva lógica da referência.

Com essa mudança de perspectiva, Mondada (2005) diz que o fenômeno da referenciação proporciona o deslocamento de um quadro estático de representação entre formas linguísticas e referentes extradiscursivos para um quadro dinâmico, no qual as práticas de referenciação di- 
recionam para a análise de aspectos organizacionais mais completos, levando em consideração elementos como contexto e espaço nas práticas enunciativas.

Por isso, a análise de objetos de discurso vai muito além das relações de paridade oriundas da simples discretização proporcionada pelo ajustamento entre palavras e coisas. Assentada nesse processo interativo, portanto, a referenciação permite a observação do caráter instável, variável e flexível das categorias, que assim o são por conta da pluralidade das relações entre a língua e o mundo, protagonizadas pelos sujeitos. Nesse contexto, os processos de referenciação são uma "[...] construção sociocognitivo-discursiva de objetos de discurso reveladores de versões da realidade e estabelecidos mediante processos de negociação" (CAVALCANTE et al, 2014, p. 41-42).

Esses processos de negociação ocorrem mediante uma série de fatores como o reconhecimento dos elementos contextuais, da (re)ativação dos conhecimentos de memória dos interactantes, além de outros aspectos que demonstram a complexidade semiótica que envolve a referenciação. Com isso, Mondada e Dubois (2003, p. 23) dizem que o que está em pauta “[...] não é mais avaliar a adequação de um rótulo 'correto', mas de descrever em detalhes os procedimentos (linguísticos e sócio-cognitivos) pelos quais os atores sociais se referem uns aos outros [...]".

Para essa tendência de abordagem, temos duas definições apresentadas por Cavalcante et al (2014) como fundamentais para o estudo da referenciação. A primeira diz respeito aos já citados objetos de discurso, os quais se caracterizam como uma entidade dinâmica estabelecida no texto, representada na mente dos interlocutores; a segunda é inerente à expressão referencial, utilizada para a manifestação formal no cotexto de uma representação do referente.

A essas definições, somam-se as ideias relacionadas aos processos referenciais que, de modo geral, são divididos em introdução referencial, anáfora e dêixis. De acordo com os autores em pauta, a introdução referencial consiste no ineditismo de um referente expresso no texto pelo uso de uma expressão referencial, sendo que a sua manifestação não tenha sido possível na mente do interlocutor diante do que é apresentado na superfície textual.

Já as anáforas, de modo sucinto, dizem respeito à possibilidade de continuidade da referência e o desenvolvimento dos objetos de discurso no texto, direta ou indiretamente. Nesse sentido, pode ocorrer a manutenção do referente com acréscimos e recategorizações responsáveis por sua reconstrução, bem como a tessitura de pontos de vista, conforme o seu desenrolar no cotexto. Nas palavras de Cavalcante (2003), as anáforas são responsáveis pela manutenção da base de referencialidade, percebida através de indícios co(n)textuais.

A classificação dos processos anafóricos ocorre, comumente, sob três formas: anáforas diretas, indiretas e encapsuladoras. A proposta classificatória de Cavalcante (2003), que amplia a visão sobre esses processos, traz dois grandes grupos anafóricos: as anáforas com retomada e as anáforas sem retomada, sendo que o primeiro agrupa os casos de anáfora direta, enquanto o segundo engloba as indiretas e as encapsuladoras.

A conceituação das anáforas diretas gira em torno da ideia de retomada de referentes previamente introduzidos, no estabelecimento de uma relação correferencial. Nesse sentido, "[...] o termo é usado para designar expressões que, no texto, se reportam a outras expressões, enuncia- 
dos, conteúdos ou contextos textuais [retomando-os ou não] contribuindo assim para a continuidade tópica e referencial" (MARCUSCHI, 2005, p. 54-55).

No tocante às anáforas indiretas, temos sua caracterização pela inexistência de um termo antecedente a ser anaforizado por meio de correferência, sendo que não há relação entre esse tipo de anáfora e o elemento que o ancora, a não ser pela natureza implícita do termo. Outro ponto peculiar a esse tipo anafórico é a percepção da anáfora indireta como constituinte de um novo referente. Para Cavalcante (2003), essas duas características fundamentam o estatuto das anáforas indiretas, que constituem continuidades referenciais sem retomada.

No que se refere às anáforas encapsuladoras, podemos nos reportar à ideia de encapsulamento anafórico, diante do que informa Conte (2003, p. 177):

O encapsulamento anafórico é um recurso coesivo pelo qual um sintagma nominal funciona como uma paráfrase resumitiva de uma porção do texto. [...] Pelo encapsulamento anafórico, um novo referente discursivo é criado sob a base de uma informação velha; ele se torna o argumento de predicações posteriores.

Nessa perspectiva, as anáforas encapsuladoras têm o papel de resumir porções textuais e, segundo Cavalcante et al (2014), exercem funções argumentativas no sentido de orientar o projeto de dizer do enunciador para um determinado ponto de vista.

Some-se, também, a ideia de rótulo retrospectivo que, segundo Francis (2003), serve para encapsular uma extensão do discurso, nomeando-a, substituindo orações e garantindo a progressão tópica. Vale dizer que o que caracteriza as anáforas encapsuladoras é a ausência de um referente pontual, apesar da recuperação de porções do texto.

Para finalizar a abordagem sobre esses processos referenciais, mencionemos os dêiticos, que são “[...] expressões linguísticas cuja interpretação se apoia nos parâmetros de lugar, tempo e pessoa da situação de enunciação [...]” (APOTHÉLOZ, 2003, p. 66).

De acordo com Cavalcante et al (2014), os dêiticos criam um vínculo entre cotexto e situação enunciativa, algo que os diferencia dos processos anafóricos. Assim, para serem identificados como tais, os dêiticos devem ter a marcação dos interlocutores, algo que proporciona a identificação do tempo e do espaço desses sujeitos.

Essa profusão que permeia os processos referenciais de modo geral concorre para uma vasta possibilidade de construção de sentidos no processo interacional que se faz pela negociação realizada entre os interlocutores em um dado contexto comunicativo. Isso é possível em função dos pressupostos que, de acordo com Koch (2001), sustentam o fenômeno da referenciação como uma atividade cognitivo-discursiva interacional, realizada por sujeitos que constroem objetos de discurso no decorrer de uma atividade discursiva em que se fazem escolhas significativas diante das possibilidades linguísticas para a construção de referentes.

Com isso, vale ressaltar que as expressões referenciais atuam com o intuito de organizar a evolução dos referentes, com sua retomada, recategorização e direcionamento para determinado ponto de vista que se queira enunciar. Essa organização parte de uma dada materialidade linguística em que se processam os sentidos negociados pelos interlocutores. Assim, "[...] a representação do funcionamento das retomadas anafóricas, e das expressões referenciais em 
geral, deve fazer intervir uma representação do sentido construído pelo texto" (APOTHÉLOZ, 2003, p. 59).

Diante dessas breves considerações, entendemos que a dinamicidade peculiar à referenciação pode se estender para a relação entre materialidades linguísticas distintas, que podem dialogar com a manutenção e retomada de referentes, bem como proporcionar a transposição de objetos de discurso e sua progressão referencial. Isso pode acontecer, por exemplo, nos casos em que se processam hipertextos, algo que nos faz levantar uma discussão acerca dos processos referenciais nessa perspectiva.

\section{0 hipertexto e os processos anafóricos}

Conforme apresentamos, os processos referenciais envolvem uma série de fatores que os fazem importantes para a produção de sentidos, a partir de uma dada materialidade linguística. Assim, subsidiados pela referenciação, podemos observar as múltiplas tarefas que concorrem para que o texto seja um lugar de reelaboração de realidade e negociação entre os sujeitos em prol do processo comunicativo. Em suma, isso se dá, entre outros aspectos, pelas construções anafóricas que dinamizam o curso textual.

Salientamos, contudo, que o estudo dos recursos anafóricos, centrado na análise da construção de sentidos em uma superfície textual, também pode ocorrer entre materialidades linguísticas distintas. Dessa forma, para além do aspecto intratextual que é conferido à anáfora de maneira mais comum, consideramos válida a discussão acerca do seu caráter intertextual e/ou hipertextual por conta de sua transitoriedade para a manutenção de referentes entre textos.

Portanto, tendo como base as características inerentes à referenciação, entendemos que a interação que envolve essa estratégia textual-discursiva, enquanto processo dinâmico e intersubjetivo que ocorre entre os interlocutores (MONDADA, 2005), também se dá em situações hipertextuais, cuja especificidade centra-se nas diversas possibilidades de direcionamento em relação aos sentidos e, por que não, em relação à percepção dos referentes.

Em nossa perspectiva de análise, é importante considerar que “[...] as palavras são elementos caracteristicamente hipertextuais pelo fato de que cada uma delas aponta e desperta potencialmente variados sentidos, conceitos e imagens [...]" (ALVES FILHO et al, 2017, p. 165). Dessa maneira, da hipertextualidade das palavras, caminha-se para uma hipertextualidade também de sentidos, visto que a construção de uma rede de sentidos ocorre a partir da exclusão de outros, ou de outras redes possíveis.

Diante disso, podemos tratar do hipertexto, com base em Araújo (2010), como uma construção que consiste em um complexo multissemiótico no qual se concentram características como a não linearidade, a presença de links que dão margem à construção de um bloco de textos conectados entre si e compõem uma teia de significados, bem como sua localização em ambientes digitais, se direcionarmos o olhar para o espectro tecnológico que, hoje, é mais aparente em relação a essa organização textual.

Em Xavier (2010), o hipertexto é entendido como "[...] uma forma híbrida, dinâmica e flexível de linguagem que dialoga com outras interfaces semióticas, adiciona e acondiciona 
à sua superfície formas outras de textualidade" (XAVIER, 2010, p. 208 - grifo do autor). Vale salientar que essa perspectiva de entendimento é centrada no caráter digital que envolve esse tipo de construção, mas há considerações acerca das características hipertextuais presentes em todo texto, como aponta Koch (2003).

Ressaltemos, assim, que a ideia de hipertexto não é totalmente nova, tendo em vista que sua organização não lhe é exclusiva, já que determinadas características hipertextuais também são percebidas em texto impressos, como pontua Braga (2010, p. 178):

Os recursos da escrita, como, por exemplo, as notas de rodapé, as referências feitas a outros textos ou as conexões explicitamente indicadas - que convidam o leitor a adiantar ou voltar atrás na leitura de um texto específico - desempenham uma função próxima daquela a ser preenchida pelos links digitais.

Apesar dessa similaridade, entendemos que as relações de interação no hipertexto virtual mostram-se de modo mais amplo em comparação ao texto escrito, pois a sua dinamicidade é maior em função de seu suporte no ciberespaço, o que permite uma movimentação mais rápida pelo fluxo de informações disponibilizadas aos sujeitos. Para Galli (2010, p. 153), o hipertexto “[...] permite todas as dobras inimagináveis, ou seja, há um movimento constante de dobramento e desdobramento de um texto e/ou das informações".

Em uma perspectiva linguística, esse movimento do hipertexto é de suma importância, haja vista as possibilidades de produção de sentido que se apresentam com os seus desdobramentos. Consideramos, também, que essa dinâmica resulta de processos anafóricos - nosso escopo de análise nesta abordagem - ou catafóricos, além de outros que, costumeiramente, são analisados em textos escritos convencionais.

Nesse sentido, salientamos que uma grande diferença em relação ao texto impresso, de acordo com Xavier (2010), refere-se à deslinearização predominante no hipertexto. Esse princípio hipertextual concorre, a nosso ver, para a percepção dos objetos de discurso da cadeia de textos que constitui o hipertexto, pois os caminhos para a sua manutenção, evolução ou recategorização diferem do que ocorre em uma materialidade linguística delimitada.

Outro ponto a ser considerado em relação ao hipertexto diz respeito à sua arquitetura textual, pois ela "[...] leva à compreensão do hipertexto como um mapeamento de associações possíveis entre textos. Isto é, a tessitura hipertextual funcionaria como uma representação das redes de sentido que estabelecemos na leitura de um texto qualquer" (CAVALCANTE, 2010, p. 203).

$\mathrm{Na}$ cadeia hipertextual, assim, percebemos a instabilidade que permeia os processos anafóricos, por conta das diferentes perspectivas de análise dos referentes. Isso porque se apresenta, no hipertexto, “[...] um esboço com caminhos sugestivos, totalmente 'violáveis', pois um dos princípios fundamentais que norteiam os construtores de hipertextos é optimização ao máximo das escolhas de trilhas no ciberespaço" (XAVIER, 2010, p. 211). Em associação a essa perspectiva, é importante observar que:

A instabilidade das categorias está ligada a suas ocorrências, uma vez que elas estão situadas em práticas: práticas dependentes tanto de processos de enunciação como de atividades cogniti- 
vas não necessariamente verbalizadas, práticas do sujeito ou de interações em que os locutores negociam uma versão provisória, contextual, coordenada do mundo (MONDADA e DUBOIS, 2003, p. 29).

Por isso, entendemos que há espaço para a análise da relação entre hipertextos e a referenciação no âmbito digital com vistas à observância do processamento anafórico hipertextual, pois os objetos de discurso transitam entre as materialidades linguísticas que compõem essa rede de textos, que é o hipertexto.

\section{Análise: 0 caráter hipertextual das anáforas}

A nossa análise, relativa ao caráter hipertextual das anáforas, parte da ideia de que os objetos de discurso presentes em uma determinada materialidade linguística podem ser transpostos para outras superfícies textuais, em retomadas anafóricas que ampliam o horizonte de observação dessa estratégia textual-discursiva.

Salientamos que os estudos sobre a referenciação estão pautados em avanços que, segundo Custódio Filho (2015), caminham para explicações sobre as muitas dimensões da configuração textual, estabelecida de modo complexo. Nessa linha de pensamento, entendemos que a configuração textual do hipertexto nos direciona para essa abrangência de análise dos processos referenciais.

Com essas considerações iniciais sobre o contexto de análise, defendemos que a associação proposta entre hipertexto e anáfora que propomos é válida, levando em consideração que “[...] ao compreendermos textos, agimos de modo hipertextual, por exemplo, saltando informações e, principalmente, fazendo associações com informações presentes em outros textos que não o que estamos a ler ou ouvir" (ALVES FILHO et al, 2017, p. 165).

Essa conectividade inerente à cadeia textual do hipertexto é responsável pelo caminho que se pode adotar em relação a um referente, além de possibilitar uma multiplicidade de escolhas maior do que se tem no texto impresso. Dessa forma, o hipertexto oportuniza escolhas que podem ser feitas ou não para a construção de sentidos, algo que ocorre também com a referenciação, considerada "[...] um processo de construção de um caminho ligando diferentes denominações aproximadas que não são excluídas pela última escolha” (MONDADA e DUBOIS, 2003, p. 30).

Para a nossa análise, enfim, elegemos dois textos, em que se constroem cadeias hipertextuais, e consideramos os links (destacados no texto) presentes nesses textos para o trânsito entre os referentes que neles se apresentam. A partir do acesso a esses links, entendemos que se dinamizam os processos referenciais anafóricos, com a transposição dos objetos de discurso entre os textos.

Vale dizer que os direcionamentos possíveis são diversos, tendo em vista a extensão das cadeias textuais do hipertexto. Todavia, analisaremos as cadeias anafóricas entre duas materialidades linguísticas apenas, com o fito de observar a transposição dos objetos de discurso e suas retomadas. 
Assim, vejamos a relação anafórica que ocorre entre os textos 01 e 02:

\section{Texto $01^{1}$}

Contaminações do coronavírus ultrapassam 2 mil em todo o mundo

Somente na China foram registrados 2.062 casos e a doença tem afetado planos da população chinesa em meio ao feriadão do Ano Novo Lunar

Thomas Peter/Reuters - 25.1.2020

O "coronavírus, surgido na cidade de Wuhan, na China", já atingiu mais de 2.116 pessoas em todo o mundo e 300 estão em estado grave. Segundo dados oficiais da província de Hubei, 52 de todas "as mortes" foram registradas na região. A capital, Wuhan, onde "o surto" teve início, é a cidade mais afetada pelo "vírus".

$[\ldots]$

O "surto" tem afetado planos da população chinesa em meio ao feriadão do Ano Novo Lunar. [...]

"A doença" também continua a se alastrar pelo mundo, com 44 casos registrados em 13 nações, além da China. A maioria dos "infectados" são "turistas" de Wuhan ou pessoas que visitaram a cidade. É o caso do terceiro "paciente" identificado na Coreia do Sul, "um homem sul-coreano" que vive em Wuhan e que havia retornado de férias ao país natal.

Texto $02^{2}$

Coronavírus: o avanço da doença que já afeta 4 continentes impactará a economia mundial?

$[\ldots]$

A China está lutando contra "um novo vírus" que matou ao menos de 56 pessoas até este domingo (26/1). "O surto do coronavírus" é uma questão de saúde tão séria que a Organização Mundial de Saúde já declarou situação de emergência no país asiático - ainda que tenha descartado, por ora, uma situação crítica global.

Inevitavelmente, "esse surto" terá também consequências econômicas. Mas quão severas elas serão e quantos países serão atingidos?

$[\ldots]$

Mas é possível identificar qual forma o impacto terá e observar os danos econômicos causados por "episódios similares" no passado, especialmente o caso da Síndrome Respiratória Aguda Severa (Sars) entre 2002 e 2003, que também começou na China.

$[\ldots]$

\footnotetext{
1 Disponível em: https://noticias.r7.com/saude/contaminacoes-do-coronavirus-ultrapassam-2-mil-em-todo-0-mundo-26012020. Acesso em: 26 jan. 2020.

${ }^{2}$ Disponível em: https://noticias.r7.com/saude/coronavirus-0-avanco-da-doenca-que-ja-afeta-4-continentes-impactara-aeconomia-mundial-26012020 Acesso em: 26 jan. 2020.
} 


\footnotetext{
"No surto atual", já é possível perceber alguns dos danos econômicos. Restrições para viagens foram adotadas para milhões de pessoas em uma época em que muitas pessoas viajam, o Ano Novo chinês. O impacto na indústria do turismo é claro, mas ainda não é mensurável.
}

No texto 01, temos a introdução referencial do objeto de discurso "coronavírus", que vai sendo desenvolvido ao longo do texto. Nessa materialidade linguística, destacamos a manutenção desse referente ao longo da superfície textual, com a presença de anáforas diretas recategorizadoras, como ocorre em "surto", "vírus" e "doença", bem como a presença de anáforas indiretas, caso de "mortes", "infectados" e "paciente", por exemplo, entre outros aspectos que demonstram a evolução do referente ao longo da superfície textual.

Essas retomadas do referente em tela permitem aos interlocutores fazerem observações acerca da elevação do número de casos do vírus, que vai sendo distribuído ao longo da superfície textual, o que fundamenta a recategorização do objeto de discurso como "surto". Com isso, é perceptível a importância das reativações ao longo da materialidade linguística para a construção de sentidos do texto e para a progressão textual.

Podemos dizer, também, que o referente "coronavírus" é desenvolvido sob o ponto de vista predominante em relação à sua expansão pelo mundo e a preocupação no que diz respeito à sua gravidade, considerado um problema de saúde com potencial de uma crise global, dado o seu rápido alastramento por diversos países e sua letalidade.

Todavia, essa orientação argumentativa proposta a partir da ativação do objeto de discurso “coronavírus", em destaque logo no início do texto 01, pode ser alterada para uma outra leitura, possível por conta do link anafórico acessível quando da ativação desse referente no texto. Assim, com o acesso ao link anafórico destacado no início do texto 01, a leitura é transportada para o texto 02 , cuja orientação argumentativa é diferente. Assim, no cotexto 02, temos bases anafóricas similares, inerentes à cadeia textual do hipertexto formado por esses dois textos analisados, mas com uma produção de sentidos distinta.

Dessa forma, enquanto o texto 01 apresenta uma orientação argumentativa voltada para a preocupação em relação à expansão do vírus no tocante a uma crise de saúde global, o texto 02 orienta, argumentativamente, para a ideia de que o surto de coronavírus pode trazer impactos para a economia mundial, assim como ocorreu em outro episódio viral, com o SARS, em 2003.

Portanto, nesses textos, o link anafórico encaminha o leitor para orientações argumentativas diferentes. Caso seja descartada a leitura proporcionada pelo link do texto 01, o referente é desenvolvido em torno da ideia de expansão do vírus pelo mundo. Se o link da introdução referencial em questão for acessado, contudo, o referente tem ampliado o seu desenvolvimento com uma construção de sentidos voltada para o seu potencial impacto na economia mundial.

Nesse sentido, consideramos que a base de referencialidade é comum para as duas materialidades linguísticas. Por isso, parece-nos que, na construção da cadeia hipertextual, também se constrói uma cadeia anafórica entre os referentes que, a nosso ver, transitam entre as materialidades linguísticas que compõem o hipertexto.

Diante dessas considerações, acreditamos que as anáforas presentes na construção de sentidos que são possíveis no hipertexto têm natureza hipertextual, pois não se prendem a uma dada mate- 
rialidade linguística e podem ativar, reativar, recategorizar, exercer seus papéis referenciais, enfim, na dinâmica textual do hipertexto, assim como ocorre nos processos anafóricos intratextuais.

Como buscamos demonstrar, a manutenção, os acréscimos, as recategorizações, entre outros aspectos das expressões referenciais que convergem para o desenvolvimento de determinado referente ocorrem em torno de um mesmo objeto de discurso. Esse referente transita por mais de uma materialidade linguística, oferecendo a possibilidade de mais de uma orientação argumentativa, além de caminhos diversos para a produção de sentidos.

\section{Considerações finais}

A discussão proposta neste artigo gira em torno da ideia de que o estudo dos processos referenciais pode ir além da análise da referenciação, enquanto estratégia textual-discursiva que se processa em uma dada materialidade linguística. Esse pensamento é sustentado pela dinamicidade que envolve o fenômeno em pauta que, a nosso ver, talvez possa ser ampliado, com a concepção de uma visão intertextual em relação às anáforas ou, no caso dos textos do ciberespaço, hipertextual.

Com esse propósito, trouxemos à tona uma breve análise acerca da possível transposição de objetos de discurso de uma materialidade linguística a outra, com a manutenção da referência, a partir da relação que se estabelece em cadeias hipertextuais.

Nessa empreitada, consideramos que é possível dizer que as anáforas também são processadas hipertextualmente, visto que, mediante o acesso a um determinado link anafórico, há a possibilidade de evolução de um objeto de discurso por meio de processos referenciais anafóricos, mas em uma materialidade linguística diferente daquela em que o referente ou a expressão referencial são ativados.

Com isso, julgamos de grande valia abordar alguns pontos importantes no tocante a essa perspectiva de análise: primeiramente, é necessário ampliar a discussão sobre as possibilidades de transposição de objetos de discurso, bem como o seu trânsito entre materialidades linguísticas distintas, como ocorre no hipertexto; um segundo ponto deve estar relacionado ao caráter inter e hipertextual das anáforas, pois se, de fato, há a possibilidade de trânsito de referentes entre cotextos distintos, isso ocorre por meio de processos referenciais anafóricos.

Assim, esperamos que essa abordagem possa suscitar discussões acerca dessa possível ampliação da análise sobre os processos referenciais anafóricos e seus desdobramentos em textos oriundos do ciberespaço.

\section{REFERÊNCIAS}

ALVES FILHO, Francisco; et al. Gêneros digitais: muito além do hipertexto. In: MARQUESI, Sueli Cristina; PAULIUKONIS, Aparecida Lino; ELIAS, Vanda Maria Linguística textual e ensino. São Paulo: Contexto, 2017. APOTHÉLOZ, Denis. Papel e funcionamento da anáfora na dinâmica textual. In: CAVALCANTE, Mônica Magalhães; RODRIGUES, Bernadete Biasi; CIULLA, Alena. (orgs.). Referenciação. São Paulo: Contexto, 2003. 
ARAÚJO, Júlio César Rosa de. Transmutação de gêneros na web: a emergência do chat. In: MARCUSCHI, Luiz Antonio.; XAVIER, Antonio Carlos. (orgs.). Hipertexto e gêneros digitais: novas formas de construção de sentido. 3 ed. São Paulo: Cortez, 2010.

BRAGA, Denise Bértoli. A comunicação interativa em ambiente hipermídia: as vantagens da hipermodalidade para o aprendizado no meio digital. In: MARCUSCHI, Luiz Antonio; XAVIER, Antonio Carlos. (orgs.). Hipertexto e gêneros digitais: novas formas de construção de sentido. 3 ed. São Paulo: Cortez, 2010.

CAVALCANTE, Marianne Carvalho Bezerra. Mapeamento e produção de sentido: os links no hipertexto. In: MARCUSCHI, Luiz Antonio; XAVIER, Antonio Carlos. (orgs.). Hipertexto e gêneros digitais: novas formas de construção de sentido. 3 ed. São Paulo: Cortez, 2010.

CAVALCANTE, Mônica Magalhães. Expressões Referenciais - uma proposta classificatória. Caderno de Estudos Linguísticos: Campinas, v. 44, pp. 105-118, jan./jun., 2003.

CAVALCANTE, et al. Coerência, referenciação e ensino. São Paulo: Cortez, 2014.

CONTE, Maria-Elisabeth. Encapsulamento anafórico. In: CAVALCANTE, Mônica Magalhães; RODRIGUES, Bernadete Biasi; CIULLA, Alena. (orgs.). Referenciação. São Paulo: Contexto, 2003.

CUSTÓDIO FILHO, Valdinar. Referenciação intertextual: análise da construção de objetos de discurso em narrativas com episódios. ReVEL, vol. 13, n. 25, 2015.

FRANCIS, Gill. Rotulação do discurso: um aspecto da coesão lexical de grupos nominais. In: CAVALCANTE, Mônica Magalhães; RODRIGUES, Bernadete Biasi; CIULLA, Alena. (orgs.). Referenciação. São Paulo: Contexto, 2003.

GALLI, Fernanda Correa Silveira. Linguagem da internet: um meio de comunicação global. In: MARCUSCHI, Luiz Antonio; XAVIER, Antonio Carlos. (orgs.). Hipertexto e gêneros digitais: novas formas de construção de sentido. 3 ed. São Paulo: Cortez, 2010.

KOCH, Ingedore Grunfeld Villaça. A referenciação como atividade cognitivo-discursiva e interacional. Caderno de Estudo Linguísticos: Campinas (41), pp. 75-89 jul./dez., 2001.

KOCH, Ingedore Grunfeld Villaça. Desvendando os segredos do texto. 2 ed. São Paulo: Cortez, 2003.

MARCUSCHI, Luiz Antonio. Anáfora indireta: o barco textual e suas âncoras. In: KOCH, Ingedore Grunfeld Villaça; MORATO, Edwiges Maria; BENTES, Anna Christina (orgs). Referenciação e discurso. São Paulo: Contexto, 2005.

MONDADA, Lorenza; DUBOIS, Danièle. Construção dos objetos de discurso e categorização: Uma abordagem dos processos de referenciação. In: CAVALCANTE, Mônica Magalhães; RODRIGUES, Bernadete Biasi; CIULLA, Alena. (orgs.). Referenciação. São Paulo: Contexto, 2003.

MONDADA, Lorenza. A referência como trabalho interativo: a construção da visibilidade do detalhe anatômico durante uma operação cirúrgica. In: KOCH, Ingedore Grunfeld Villaça; MORATO, Edwiges Maria; BENTES, Anna Christina (orgs). Referenciação e discurso. São Paulo: Contexto, 2005.

XAVIER, Antonio Carlos. Leitura, texto e hipertexto. In: MARCUSCHI, Luiz Antonio; XAVIER, Antonio Carlos. (orgs.). Hipertexto e gêneros digitais: novas formas de construção de sentido. 3 ed. São Paulo: Cortez, 2010. 